\title{
Cálculo de los componentes estructurales del déficit público español (1992-2015)*
}

\author{
IgNACIO MARTÍNEZ FERNÁNDEZ a , LUIS PALMA MARTOS a , CHRISTIAN CHASE \\ SOLÁN ${ }^{\mathrm{a}}$ \\ a Universidad de Sevilla, Cátedra de Política de la Competencia, Avda. Ramón y Cajal, 1, 41018 \\ Sevilla, España.E-mail: ignmarfer1@gmail.com, lpalma@us.es, christian.chasesolan@gmail.com
}

\begin{abstract}
RESUMEN
La entrada en recesión de la economía española en 2009 reavivó el debate sobre el papel del déficit público en el devenir económico, aunque poco se ha profundizado sobre las causas y la naturaleza de los desequilibrios en las cuentas públicas. Mediante un detenido estudio de los presupuestos y la elaboración de un modelo de regresión, desagregando las componentes principales del saldo presupuestario, abordaremos dicha cuestión. Contrariamente al relato popular, nuestros resultados indican cómo la estabilidad presupuestaria fue el hecho coyuntural y la existencia de un déficit primario durante el periodo 1992-2015 del 3,30\% del PIB de media, la regla.
\end{abstract}

Palabras clave: Déficit Público, Déficit Financiero, Déficit Estructural, Deuda Pública.

\section{Calculating the Structural Components of the Spanish Public Deficit (1992-2015)}

\begin{abstract}
As the Spanish economy slid into recession during 2009, the debate over the role of the public deficit came into the spotlight once again. However, there has been little emphasis on determining the causes and the nature of the imbalances in the government's accounts. We study the structure of aggregate public budgets and use regression analysis to address these two issues. Contrary to the conventional wisdom, our results show that budget's stability was transitory and that, in reality, an average primary deficit of 3,30\% of GDP prevailed throughout the years between 1992 and 2015.
\end{abstract}

Key Words: Public Deficit, Financial Deficit, Structural Deficit, Public Debt

Clasificación JEL: H11, H62

\footnotetext{
* Una versión preliminar de este artículo fue galardonado con el premio Bernardo Pena para jóvenes investigadores durante el XXX Congreso Internacional de Economía Aplicada, ASEPELT2016, celebrado en Valencia y que ha contado con el patrocinio de la Consellería de Educación, Investigación, Cultura y Deporte de la Generalitat Valenciana. Se agradece la financiación para la publicación de este artículo.
}

Artículo recibido en junio de 2016 y aceptado en julio de 2016

Artículo disponible en versión electrónica en la página www.revista-eea.net, ref. ə-34303 


\section{INTRODUCCIÓN}

Tras el shock de la crisis económica global en 2008 y su deriva en crisis de deuda soberana en la Unión Europea, se pusieron de manifiesto problemas de coordinación institucional, así como la rigidez de los criterios adoptados en el Tratado de Maastricht a la hora de afrontar shocks asimétricos. La sucesión de expedientes de déficit excesivo diluyó la confianza en la solvencia de varios Estados Miembros, lo que llevó a la firma de los Memorándums de Entendimiento, y al establecimiento de sendas de reducción del déficit público, en contraprestación al apoyo financiero recibido.

En este contexto es preciso conocer la naturaleza de los déficits que acarrean los Estados, con el fin de comprender la viabilidad, y en su caso la dureza, de las medidas necesarias para equilibrar las cuentas públicas. El objetivo de este trabajo será estudiar la naturaleza y componentes del déficit (o superávit) del Estado español durante el periodo 1992-2015. Para ello, en primer lugar, elaboraremos un breve repaso de la literatura y los eventos recientes que nos permita contextualizar nuestra hipótesis de trabajo; en segundo lugar, plantearemos nuestra modelización y el proceso de elaboración del conjunto de datos necesario; en tercer lugar, desarrollamos el análisis de los resultados y la realización de algunos estudios complementarios que nos permitan completar dicho análisis; por último, presentaremos las conclusiones derivadas del trabajo.

\section{EL CAMINO HASTA HOY}

\subsection{La Unión Económica y Monetaria como marco institucional. Crisis y cambio de paradigma}

Con la firma, el 7 de Febrero 1992, del Tratado de la Unión Europea ${ }^{1}$ (conocido popularmente como Tratado de Maastricht), se dio el paso definitivo hacia la constitución de la Unión Económica y Monetaria, mediante la fijación de los criterios de convergencia de la futura Zona Euro. Estos criterios se centraron, principalmente, en que los Estados se dotaran de un margen de maniobra financiero para poder sortear los posibles shocks económicos asimétricos, derivados de la constitución de una unión monetaria incompleta (De Grauwe, 2014). Se resumían en ${ }^{2}$ :

- Estabilidad de precios. La tasa de inflación de un Estado miembro dado, observada durante un período de un año antes del examen, no debe rebasar en más de 1,5 puntos porcentuales la de los tres Estados miembros con mejor comportamiento en materia de estabilidad de precios.

\footnotetext{
${ }^{1}$ Entraría en vigor el 1 de noviembre de 1993.

${ }^{2}$ Convergence criteria, artículo 121, apartado 1, del Tratado constitutivo de la Comunidad Europea. Consultado en European Union Law. Última actualización: 12.07.2006
} 
- Finanzas públicas. Con una doble vertiente, por el lado del déficit público su proporción anual en el producto interior bruto no debería rebasar el 3 \% al final del ejercicio presupuestario; respecto de la deuda pública, ésta no debería exceder el 60\% del PIB al final del ejercicio presupuestario.

- Tipos de cambio. Los Estados Miembros deberían haber participado en el mecanismo de tipos de cambio del sistema monetario europeo sin interrupción durante los dos años anteriores, sin haber sufrido tensiones graves. Por otra parte, no debían haber llevado a cabo devaluación por iniciativa propia de su moneda durante este mismo período.

- Tipos de interés a largo plazo. El tipo de interés nominal medio a largo plazo no debería rebasar en más de dos puntos porcentuales el de los tres Estados miembros con mejor comportamiento en materia de estabilidad de precios.

Unido a esta senda de convergencia se estableció un mecanismo corrector, encarnado en el Procedimiento de Déficit Excesivo (PDE). Los Estados comprometidos con el Pacto de Estabilidad y Crecimiento (PEC) aceptaban seguir una serie de recomendaciones que les permitieran revertir el desequilibrio en sus cuentas públicas y les devolviese a la senda de crecimiento bajo pena $\mathrm{de}^{3}$ :

- La obligación de abonar a la Comisión un depósito con intereses del 0,2% del PIB en la fase preventiva;

- La obligación de abonar un depósito sin intereses del 0,2 \% del PIB en la fase correctora. Este depósito se convierte en una multa de hasta el 0,5 \% del PIB si no se siguen las recomendaciones para corregir el déficit excesivo.

\subsubsection{Crisis financiera global y cambio de paradigma. El caso español}

Las instituciones y mecanismos antes descritos se mantuvieron con cierto éxito, y algunos fracasos sonados ${ }^{4}$, hasta el estallido de la crisis económica y financiera en el año 2008. Al contrario de las turbulencias económicas que habían logrado capear las instituciones europeas con anterioridad, este shock mostró las grietas y fragilidad de los mecanismos de cooperación europea. Ante la acumulación de continuos y crecientes déficits fiscales por parte de diferentes Estados miembros, urgía una respuesta por parte de las instituciones comunitarias. Era preciso articular un mecanismo que permitiera prestar apoyo financiero a los Estados que lo precisaran sin que ello derivara en un problema de riesgo moral entre deudores y acreedores.

\footnotetext{
${ }^{3}$ Este procedimiento no se articulaba de forma instantánea, dado que su objetivo no es la penalización sino fomentar la prudencia.

${ }^{4}$ Véase los déficits sostenidos por Alemania tras la reunificación.
} 
La respuesta a esta disyuntiva se concretó en los conocidos como Memorándums de Entendimiento (o MoU, por sus siglas en ingles). En estos acuerdos se estipulan las condiciones, en términos de montante y duración, de la asistencia financiera y su contraparte en forma de reformas estructurales, que permitan revertir la situación de insolvencia (o iliquidez) por la que temporalmente atraviese un Estado miembro.

El camino seguido por España resulta un caso de estudio interesante por su singularidad ${ }^{5}$, tanto en los mecanismos empleados como por la situación de partida. Respecto a esta última cuestión, España había disfrutado durante cerca de una década de un proceso continuo (y por etapas acelerado) de crecimiento y desarrollo económico, que posicionó al Estado como uno de los menos endeudados de nuestro entorno ${ }^{6}$. Ante el estallido de la crisis económica y financiera se optó inicialmente por cubrir el gap entre gastos e ingresos en las cuentas públicas mediante sucesivas emisiones del Tesoro, política que parecía razonable si tenemos en cuenta los bajos niveles de endeudamiento público (35,50\% del PIB a finales de 2007), una estrategia que se vino abajo ante el deterioro progresivo de la liquidez en los mercados internacionales, que comenzaban a descontar la posibilidad de un shock de deuda soberana en la eurozona. El fuerte crecimiento que estaba experimentando la deuda pública (19\% medio anual), unido a unas condiciones de acceso a la financiación cada vez más duras, desembocó en la reforma del artículo 135 de la Constitución.

Esta controvertida medida mostraba el compromiso del Gobierno con los inversores, al posicionar a los tenedores de deuda pública del Estado como acreedores preferentes en la prelación de crédito, supeditando el resto de desembolsos al pago de intereses de la deuda. Junto a esta medida, se incorporaron los criterios de estabilidad presupuestaria para los diferentes ámbitos de la Administración. A pesar de estos cambios, e incluso tras una tímida reforma fiscal en 2010, la situación del saldo presupuestario no tenía visos de mejorar, y menos aún de ser capaz de absorber los costes de saneamiento de un sistema, que comenzaba a tambalearse.

En 2012 el Gobierno de España y las instituciones europeas alcanzaron un acuerdo $^{7}$ que habilitaba una línea de crédito para sufragar el proceso de reestructuración del sistema financiero español. Sin embargo, ni el apoyo de las autoridades comunitarias, ni tampoco el claro compromiso del Gobierno por

\footnotetext{
${ }^{5}$ No es nuestro objetivo entrar a valorar las decisiones y medidas tomadas, sino su exposición.

${ }^{6}$ Fruto de la combinación entre liquidación de activos públicos, reforma del sistema fiscal y fuerte crecimiento de los niveles de renta y empleo.

${ }^{7}$ El Memorándum de Entendimiento entre España y la Comisión fue presentado el 20 de julio de 2012.
} 
implementar un inminente plan de reformas ${ }^{8}$, fueron capaces de estabilizar los mercados de deuda, y la prima de riesgo continuó su senda alcista, superando los 600 puntos básicos. La posibilidad de que otro miembro de la Unión Monetaria pudiera caer en bancarrota, poniendo en juego la Moneda Única, llevó a Mario Draghi a proclamar $^{9}$ "[...], the ECB is ready to do whatever it takes to preserve the euro. And believe me, it wil be enough."

\subsubsection{El déficit sostenidamente (in)sostenible de la Hacienda Pública española}

Una vez hemos esbozado las líneas maestras del marco institucional europeo, y de los mecanismos que se articulan respecto al déficit, hagamos un repaso de la trayectoria española al respecto.

A la hora de estudiar el comportamiento de las cuentas públicas españolas hasta el año 2005 seguiremos el trabajo desarrollado en Rubio (2007), ampliando la serie hasta 2015. Los datos obtenidos están expuestos en la Tabla 1, en la cual se pone de manifiesto el largo historial de déficit en las cuentas públicas que arrastra España.

Tabla 1

Saldo presupuestario medio en porcentaje del PIB

\begin{tabular}{|l|c|c|c|c|c|c|c|c|}
\hline Periodo & $1976 /$ & $1981 /$ & $1986 /$ & $1991 /$ & $1996 /$ & $\mathbf{2 0 0 1 /}$ & $\mathbf{2 0 0 6 /}$ & $\mathbf{2 0 1 1}$ \\
& 1980 & 1985 & 1990 & 1995 & $\mathbf{2 0 0 0}$ & $\mathbf{2 0 0 5}$ & $\mathbf{2 0 1 0}$ & $\mathbf{2 0 1 5}$ \\
\hline Saldo presupuestario & $-1,34$ & $-5,02$ & $-4,04$ & $-5,62$ & $-2,66$ & 0,02 & $-4,12$ & $-7,56$ \\
\hline
\end{tabular}

Fuente: Rubio (2007) y Eurostat.

Podemos apreciar cómo en el saldo presupuestario entre los años 1976 y 2005, el déficit ha sido la norma. Este estudio se ve complementado con los estudios de Bajo-Rubio et al. (2004 y 2006), que nos presentan el comportamiento dinámico de la Hacienda Pública española como no lineal, lo cual les permite concluir que sólo se procedería a una consolidación fiscal en caso de alcanzarse un déficit "demasiado grande" que ellos cifran en el 5,3\% del PIB para el periodo 1964-2003.

\subsection{El análisis económico del marco institucional}

Pasemos ahora a desentrañar la explicación económica que subyace en la construcción y evolución de este complejo institucional.

\footnotetext{
${ }^{8}$ De hecho el plan de reformas se inició con la aprobación del Real Decreto-ley 20/2012 de 13 julio.

${ }^{9}$ Intervención en Global Investment Conference in London 26 July 2012. Consultar nota de prensa en: https://www.ecb.europa.eu/press/key/date/2012/html/sp120726.en.html (consultado 2/5/2016).
} 


\subsubsection{Criterios de Maastricht e independencia del Banco Central Europeo ${ }^{10}$}

Los objetivos de convergencia que citábamos anteriormente perseguían, si bien es cierto que de forma defectuosa, al observar indicadores nominales en lugar de reales, la convergencia de las diferentes economías europeas y con ella el desarrollo de un auténtico mercado único dentro de la Unión Europea.

La independencia ${ }^{11}$ del Banco Central, y su prioridad en el mantenimiento de la estabilidad de precios, si bien es cierto que hunde sus raíces en la historia y en la correlación de fuerzas durante las negociaciones que llevaron a su constitución, tiene también una fundamentación económica. En nuestro sistema monetario, basado en moneda fiat ${ }^{12}$, la lucha contra la inflación y el establecimiento de criterios objetivos sobre la emisión, son esenciales para mantener la credibilidad y el valor de la moneda; a esto debemos añadir los problemas derivados de la construcción de una Unión Monetaria incompleta, como es eurozona, y la tentación de emplear el trade-off entre inflación y desempleo con fines políticos.

\subsubsection{Reforma del artículo 135 de la Constitución española}

El objetivo que perseguía la reforma constitucional, no era otro que generar una señal que diferenciara nuestra deuda pública en los mercados internacionales, reforzando su imagen de activo con garantías, para reducir así el componente de prima por riesgo de impago en las operaciones de endeudamiento.

\subsubsection{La supervisión financiera y el calendario de ajuste fiscal en el MoU}

Esta característica viene de alguna forma "importada" de los procesos concursales desarrollados en el derecho privado, con el añadido de establecer un mecanismo reglado de incentivos y sanciones. Esta cláusula pretende minimizar el riesgo moral inherente a los procesos de asistencia y mutualización de deuda, a la par que dota de credibilidad a la transitoriedad de dicha asistencia financiera.

\subsection{Vías de consolidación del déficit}

Probablemente este sea el punto más controvertido, dada variedad de posturas que existen al respecto. Partamos de que la consolidación fiscal ha de llevarse a cabo en tanto forma parte, tanto del MoU firmado por el Gobierno de

${ }^{10}$ Para un análisis pormenorizado, consultar Barro y Gordon (1987); y De Greuwe (2014), pp. 133-140.

${ }^{11}$ Bastante discutida, tanto en el pasado como actualmente.

${ }^{12}$ Entendiendo dinero fiat o fiduciario aquellos medios de pago carentes de patrón de convertibilidad en bienes reales y que por tanto se emiten contra promesas de pago, es decir, cuyo colateral en el balance del emisor son deudas. 
España en 2012 como del PEC, de modo que la cuestión se centra en plazos y medios.

En este sentido, y asumiendo que el objetivo perseguido es una reducción con carácter permanente de déficit público, nos encontramos con tres enfoques. De acuerdo con el punto en torno al que debe articularse esta política ${ }^{13}$ :

- Reducción del gasto y reformas estructurales: En Alesina y Perotti (1995) se concluye que la reducción del déficit de forma permanente sólo es posible abordando reducciones en el gasto.

- Aumento de los ingresos y reformas estructurales: En Conde-Ruiz y Marín (2013) se plantea la combinación de una reforma fiscal que aproxime tipos marginales y tipos medios efectivos con reformas estructurales que permitan un mayor crecimiento.

- Reformas estructurales: En Andrés et al. (2016) se estima la reducción del déficit mediante la actuación de los estabilizadores automáticos, una vez se consoliden las reformas que permitan a España mantenerse próxima a su senda de crecimiento potencial.

\subsection{Nuestras hipótesis de trabajo}

Una vez presentados los datos relativos al saldo presupuestario y caracterizado el marco jurídico e institucional en que nos encontramos, podemos pasar a exponer nuestras hipótesis de trabajo.

I. El déficit presente de debe a una estructura de gasto primario generada sobre la base de ingresos extraordinarios e ingresos coyunturales.

II. Esta estructura de gasto conlleva el reconocimiento y consolidación de obligaciones presupuestarias inasumibles para el nivel de ingresos corriente.

\section{DATOS Y SU MODELIZACIÓN}

\subsection{Nuestro conjunto de datos}

Para la construcción de nuestra base de datos optamos por recurrir a la extracción directa de las cuantías de los Presupuestos Generales del Estado (PGE) para el periodo 1992-2015. Como fuentes de datos complementarias nos dirigimos a Eurostat, el Instituto Nacional de Estadística (INE), al Tesoro y a los boletines de información económica del Banco de España. Conviene ahora exponer las operaciones que hemos realizado para adaptar los datos brutos a las categorías que definimos anteriormente.

${ }^{13}$ Un análisis coste-beneficio preliminar de las diferentes combinaciones de medidas y plazo puede encontrarse en De Cos (2010). 
La primera de las operaciones que debemos acometer es convertir los saldos corriente y financiero en saldos primario y secundario respectivamente. Para ello tomaremos los datos brutos de los PGE y, tal como se recoge en la Tabla 2, restamos la partida dedicada a los servicios (pagos) de la deuda del gasto corriente y la añadimos al gasto financiero.

Determinar el componente estructural en el saldo presupuestario requerirá una serie de pasos y definiciones preliminares:

Ingresos extraordinarios. Definiremos los ingresos extraordinarios como aquellos que se generan en un único periodo, a partir de una transacción puntual, o generados por un hecho imponible que no se dilata en el tiempo. De acuerdo con esta definición, consideraremos como ingresos extraordinarios aquellos devengados por las operaciones de liquidación del patrimonio empresarial público (1992-2015) y los excedentes de recaudación por los impuestos de Transmisiones Patrimoniales y Actos Jurídicos Documentados (ITP y AJD) y sobre el valor añadido (IVA) afectos a la actividad inmobiliaria durante el periodo de burbuja inmobiliaria y a la obra civil (1999-2010). Para calcular la cuantía del exceso recaudatorio nos hemos basado en la metodología seguida en Conde-Ruiz y Marín (2013) e iterado su proceso de cálculo para cada año del periodo de referencia. El peso de estos ingresos extraordinarios sobre los ingresos totales del sector público aparece recogido en la Figura 1.

Figura 1

Volumen de ingresos extraordinarios sobre total de ingresos 1992-2015

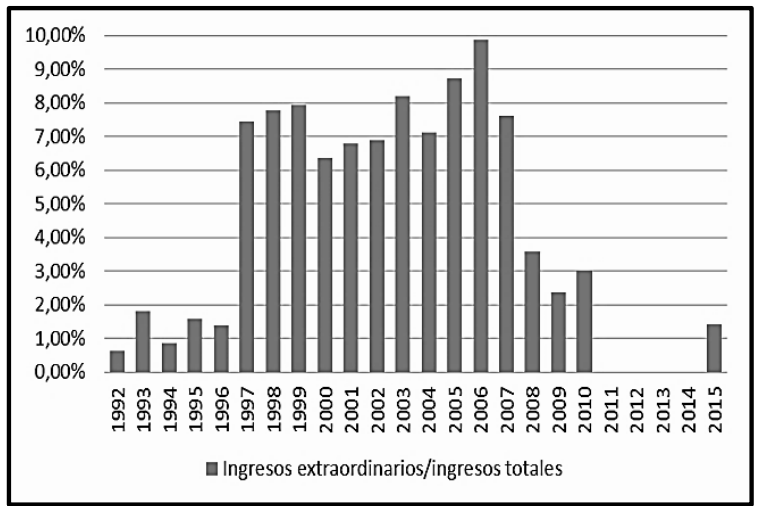

Fuente: Elaboración propia.

Desempleo coyuntural vs desempleo estructural. La definición canónica de desempleo estructural o desempleo NAIRU (Non-Accelerating Inflation Rate of Unemployment en inglés) presenta ciertos problemas cuando es aplicada a una estructura productiva como la española. Esta adolece de problemas como la existencia de un componente estructural en la tasa de inflación o un mercado 
laboral altamente rígido, lo cual dificulta seriamente el cálculo del nivel de desempleo estructural. Debido a estas complejidades, hemos optado por apoyarnos en las cifras de Andrés et al. (2016), que sitúan el desempleo estructural medio de la economía en torno al 18\% de la población activa. Tomando esta tasa como límite superior, y teniendo en cuenta el sesgo que genera el empleo de medias aritméticas, nos decantamos por considerar como desempleo estructural para el periodo 1992-2015 su tasa de desempleo modal, el 16,85\%.

Con estos datos pasamos a determinar el coste presupuestario de las prestaciones que, dado que no se encuentran como partida presupuestaria independiente hasta los PGE del año 2005, aproximaremos a través de los cálculos de Espuelas (2013) sobre la evolución del gasto social. Al correlacionar el gasto en prestaciones con la tasa de desempleo de cada año podemos, de forma complementaria, recoger los cambios sufridos en la tasa de cobertura de la prestación por desempleo.

El saldo de la Seguridad Social. El sistema de la Seguridad Social emanado de los Pactos de Toledo en 1995, y basado en un esquema PAYG (Pay As You Go en inglés) partía del equilibrio presupuestario entre cobros y pagos del sistema, como regla básica de funcionamiento, lo cual excluía en términos prácticos la existencia de déficit o superávit presupuestarios. Este modelo se mantuvo vigente hasta la constitución, en el año 2000, del Fondo de Reserva de la Seguridad Social, como garantía de las prestaciones contributivas frente a futuros desequilibrios en el saldo presupuestario de la Seguridad Social de naturaleza coyuntural. Asumiremos que, a efectos prácticos y con carácter general, la existencia de déficit o superávit en la Seguridad Social atenderá a factores estrictamente coyunturales, fruto de las fluctuaciones en el nivel de actividad ${ }^{14}$.

Podrá sorprender al lector la ausencia de estimaciones sobre el exceso recaudatorio en materia de Impuesto de Sociedades (IS) o de Impuesto sobre Renta de las Personas Físicas (IRPF). Debemos puntualizar que su exclusión se debe a la imposibilidad de desagregar el carácter extraordinario de la recaudación imputable a la burbuja de activos, del efecto desborde sobre otros sectores. Para poder evitar una sobreestimación del carácter extraordinario de estos ingresos, que en parte se encuentra reflejado en los excesos recaudatorios por IVA, hemos optado por considerar la variación de recaudación por IS e IRPF como estrictamente coyuntural. En Conde-Ruiz et al. (2015), se estima un excedente recaudatorio del sistema impositivo en su conjunto próximo al 4\% del PIB.

\subsection{Definición de los componentes del déficit y su modelización}

A la hora de estudiar el saldo presupuestario de las cuentas públicas debe-

${ }^{14}$ Esta postura contrasta con Martínez y Palma (2015), donde se asume un desequilibrio estructural sobre las previsiones demográficas a medio plazo. 
mos, en primer lugar, proceder a definir los componentes a estudiar, así como organizarlos de forma taxonómica. Esta clasificación viene recogida en la Tabla 2:

Tabla 2

Taxonomía y desagregación del saldo presupuestario

\begin{tabular}{|c|}
\hline Saldo Fiscal (1) = Saldo Corriente (2) + Saldo Financiero (3) \\
\hline Saldo Corriente (2) = Saldo Primario (4) + Servicios de deuda (5) \\
\hline Saldo Primario (4) = Saldo Estructural (6) + Saldo Coyuntural (7) \\
\hline Saldo Secundario (8) = Saldo Financiero (3) + Servicios de deuda (5) \\
\hline Saldo Coyuntural (7)= Gastos Coyunturales (9) + Ingresos Extraordinarios (10) \\
\hline
\end{tabular}

Fuente: Elaboración propia.

De acuerdo con la taxonomía que hemos establecido sobre la naturaleza del saldo presupuestario, nos planteamos, en primer lugar, una aproximación de naturaleza estadística que nos permita observar las componentes del análisis clásico de sostenibilidad del déficit público.

\section{Figura 2}

Descomposición del déficit público en las componentes del estudio clásico de sostenibilidad

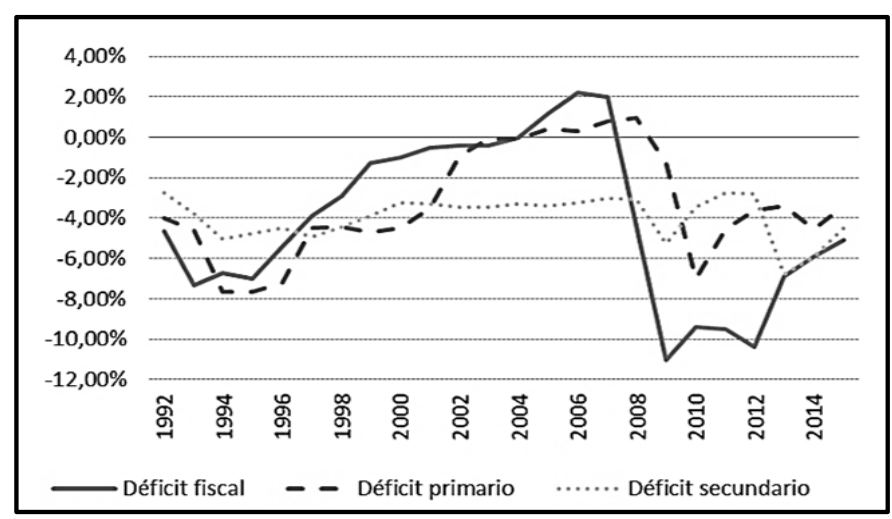

Fuente: Elaboración propia.

Observando la evolución y cambios en la tendencia de las series representadas en la Figura 2 podemos apreciar 4 fases o patrones:

- 1992-1996. España se encuentra en proceso de recuperarse de los efectos adversos del "boom" inmobiliario sufrido por la economía española a finales de la década de 1980 y los coletazos del proceso de reconversión industrial y convergencia hacia la naciente Unión Europea.

- 1997-2008. El “ciclo virtuoso" de la economía española. La fuerte caída de los tipos de interés, tanto en el crédito al sector privado como al pú- 
blico, unida a una favorable coyuntura económica, alimentó un acelerado crecimiento de la economía española y una fuerte reducción del desempleo a lomos de la mayor burbuja de activos de nuestra historia reciente. Lo cual se tradujo en un crecimiento medio anual de los ingresos, próximo al 5,5\% para el sector público.

- 2009-2013. Crisis y recesión económica. El hundimiento del sector de la construcción arrastró en su caída a toda la economía española; no ha de extrañar, si tenemos en cuenta que en 2006 las transacciones de vivienda libre llegaron a suponer el $16 \%$ del PIB $^{15}$. La caída en el nivel de actividad pronto degeneró en una crisis presupuestaria con la consolidación de importantes déficits del sector público, que llegaron a poner en serias dudas la propia solvencia del Estado.

- 2014-2015. Consolidación y vuelta del crecimiento. La fuerte reestructuración experimentada por el sector privado durante la fase anterior, permitió al tejido empresarial aprovechar la favorable coyuntura económica ${ }^{16}$, de lo que parece consolidarse como un nuevo cambio de tendencia.

Tras esta segmentación del periodo de estudio, de acuerdo con los acontecimientos históricos y los hechos estilizados observables, pasamos a plantear nuestra modelización del Saldo presupuestario:

Saldo Fiscal $_{t}=$ Saldo Estructural $_{t}+$ Saldo Financiero $_{t}+$ Saldo coyuntural $_{t}$

\section{ANÁLISIS DE RESULTADOS}

Para proceder a la estimación del modelo de regresión nos hemos decantado por emplear el software econométrico gretl y como método de estimación la regresión lineal con corrección de heterocedasticidad.

\subsection{Resultados principales y sus implicaciones}

Estos resultados nos permiten profundizar en el análisis que anteriormente desarrollamos a través de la estadística descriptiva:

1) Tanto las variables individuales como el modelo en su conjunto resultan estadísticamente significativos.

2) La serie estimada presenta un buen ajuste respecto a las variables observadas.

3) El valor de los parámetros no permite validar de forma contundente nuestras hipótesis de partida.

\footnotetext{
${ }^{15}$ Según datos del propio Ministerio de Fomento.

${ }^{16}$ Esta coyuntura positiva, desde la perspectiva española, sienta sus bases en las fuertes caídas del precio del petróleo, la depreciación del euro y la estabilización del mercado de crédito.
} 
Tabla 3

Resultados de estimación de nuestro modelo de regresión

\begin{tabular}{|lccccc|}
\hline & Coeficiente & Desv. Típica & Estadístico t & Valor $\mathbf{p}$ \\
\hline Saldo Estructural & 0.198204 & 0.0668451 & 2.9651 & 0.0074 & $* \star \star$ \\
Saldo Financiero & 0.582887 & 0.0618142 & 9.4297 & $<0.0001$ & $* \star \star$ \\
Saldo Coyuntural & 0.61858 & 0.0463639 & 13.3419 & $<0.0001$ & $* \star \star$ \\
Suma de cuad. residuos & 25.18410 & & D.T. de la regresión & 1.09509 \\
R-cuadrado & 0.914867 & R-cuadrado corregido & 0.90676 \\
F(3, 21) & 75.22475 & Valor p (de F) & $2.12 \mathrm{e}-11$ \\
\hline
\end{tabular}

Fuente: Elaboración propia.

Nos preguntamos a que podría deberse el papel menos relevante del déficit estructural en nuestra modelización de lo que podía preverse, a la luz del análisis preliminar de datos, e identificamos las siguientes causas posibles:

i. El nivel de agregación con que estamos trabajando no permite un análisis todo lo preciso que nos gustaría.

ii. Las definiciones y la operativa realizada en la construcción del conjunto de datos pueden resultar incompletas al no considerar el posible trasvase entre partidas.

\subsection{Estudios complementarios}

Una vez presentados los resultados principales de nuestra modelización nos planteamos los siguientes estudios que permitan, dentro de las limitaciones de la base de construida, completar aspectos adyacentes sobre el estudio del déficit público:

Déficit público, deuda y el coste del endeudamiento

Figura 3

Evolución de la Deuda Pública y los intereses

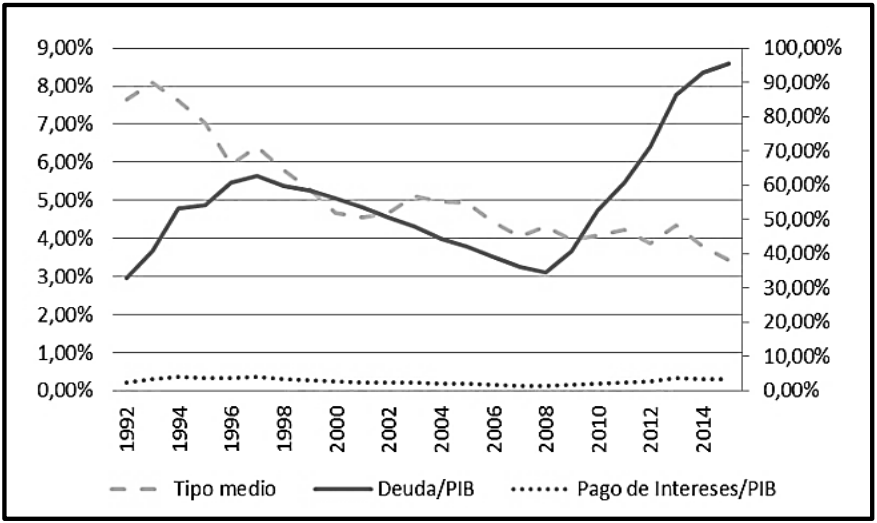

Fuente: Elaboración propia. 
Un argumento muy popular sobre el aumento del déficit público y su sostenibilidad parte de considerar como origen de su existencia la carga financiera derivada de la imposibilidad de monetizar dichos déficits. Los resultados obtenidos muestran que, siendo representativo el pago de intereses de la deuda, el factor determinante no es el tipo de interés con que se retribuye a los tenedores sino su creciente volumen en circulación. Esto reabre el debate sobre el papel disciplinante que imprime el coste del endeudamiento sobre el crecimiento del volumen de deuda. La Figura 3 nos muestra estas tendencias.

\section{Rigideces en el gasto y flexibilidad en el ingreso}

Debido a los llamados estabilizadores automáticos, existe un carácter diferencial en el comportamiento que presentan el gasto y el ingreso público respecto a las variaciones del PIB. Este comportamiento, contra cíclico y pro cíclico respectivamente, se traduce en diferentes grados de elasticidad de gasto e ingreso respecto al PIB. Para contrastar la existencia de dicho comportamiento en los PGE hemos optado por medir la elasticidad de gasto e ingreso respecto al PIB. Los resultados para la serie completa de datos nos indican, no sólo que tanto gasto como ingreso presentan un comportamiento pro cíclico ${ }^{17}$, sino que de hecho la elasticidad del gasto respecto del PIB es mayor que la del ingreso. Tratando de evitar problemas de compensación a lo largo del ciclo, repetimos el test segmentando la muestra en los periodos planteados en el apartado 3.1., obteniendo resultados (ver Tabla 3) que revalidan nuestra conclusión anterior.

Tabla 4

Elasticidad de ingreso y gasto público respecto al PIB

\begin{tabular}{|l|c|c|c|c|}
\hline Periodo & $\mathbf{1 9 9 2 - 1 9 9 6}$ & $\mathbf{1 9 9 7 - 2 0 0 8}$ & $\mathbf{2 0 0 9 - 2 0 1 3}$ & $\mathbf{2 0 1 4 - 2 0 1 5}$ \\
\hline Elasticidad ingresos & 0.9089 & 0.9054 & 0.9037 & 0.9062 \\
\hline Elasticidad gastos & 0.9302 & 0.9199 & 0.9230 & 0.9271 \\
\hline
\end{tabular}

Fuente: Elaboración propia.

\section{Presencia de histéresis en el déficit público}

La posibilidad de que exista un problema de histéresis en el comportamiento del saldo del sector público supondría un importante contratiempo en el esfuerzo hacia la consolidación fiscal, de ahí que nos propongamos contrastar dicha hipótesis. Para llevar a cabo el análisis, repetimos la estimación del modelo incluyendo como variable explicativa el saldo fiscal retardado un periodo.

Los resultados obtenidos validan nuestra hipótesis de que, efectivamente, existe un problema de histéresis en el saldo presupuestario, convirtiéndose en la única variable individualmente significativa:

${ }^{17}$ Podemos encontrar resultados análogos en Conde-Ruiz et al. (2015). 
Tabla 5

Resultados de estimación bajo la presencia de histéresis

\begin{tabular}{|lcccc|}
\hline & Coeficiente & Desv. Típica & Estadístico t & Valor $\mathbf{p}$ \\
\hline Saldo Estructural & -0.0949316 & 0.169713 & -0.5594 & 0.5824 \\
Saldo Financiero & 0.174841 & 0.172122 & 1.0158 & 0.3225 \\
Saldo Coyuntural & 0.203043 & 0.145737 & 1.3932 & 0.1796 \\
Saldo Fiscal (t-1) & 0.752527 & 0.180227 & 4.1754 & 0.0005 \\
Suma de cuad. residuos & 31.13345 & & D.T. de la regresión & 1.280079 \\
R-cuadrado & 0.951844 & & R-cuadrado corregido & 0.944240 \\
F(4, 19) & 93.88772 & & Valor p (de F) & $3.07 e-12$ \\
\hline
\end{tabular}

Fuente: Elaboración propia.

\section{CONCLUSIONES}

En este trabajo hemos examinado la evolución del déficit público a través de sus componentes principales, y estudiado el marco jurídico-institucional en torno a la estabilidad presupuestaria. A pesar de que nuestra muestra no es excesivamente amplia, nos permite capturar la evolución del déficit público en un periodo de cambios acelerados, tanto en la estructura del Estado, con la consolidación del Estado del Bienestar, como de la economía, con el proceso de integración europea, desde la puesta en marcha del Mercado Único hasta la primera gran crisis económica y financiera de la Unión Económica y Monetaria.

Hemos podido contrastar la existencia de un componente estructural dentro del saldo presupuestario primario, cuyo valor medio durante el periodo observado es del $-2,37 \%$ del PIB. La magnitud del déficit estructural supone un freno importante al uso discrecional de la política fiscal, en el marco de los límites de déficit presupuestario acordados en el Tratado de Maastricht, como herramienta contra cíclica. Estas cifras chocan frontalmente con el extendido relato, tanto dentro de la Administración como en la propia sociedad, del “déficit sobrevenido" en la cuentas públicas. Un estudio en profundidad del saldo presupuestario del Estado nos presenta una imagen desoladora donde el equilibrio (o superávit) presupuestario es anecdótico, sólo se alcanza en el periodo 2004-2007, siendo la tónica general un déficit promedio superior al $5 \%$ del PIB.

A la hora de afrontar la consolidación de las cuentas públicas, podemos observar dos líneas de actuación bien diferenciadas: el ajuste puntual y el ajuste tendencial. Por ajuste puntual nos referimos a la política de "maquillaje" de las cuentas públicas mediante el adelgazamiento del sector público. Esta política fue la seguida principalmente durante el periodo 1992-2001 y vuelve a emplearse desde la entrada en recesión en el año 2008. El ajuste tendencial es una combinación entre políticas de gasto e ingreso, conteniendo el crecimiento de los desembolsos e incrementando la capacidad recaudatoria, cuya 
plasmación más evidente son las reformas fiscales y los planes de racionalización del gasto público.

No podemos concluir este trabajo sin poner de manifiesto su carácter preliminar, cuya utilidad radica en las posibles investigaciones que de él se deriven más que de los propios resultados obtenidos.

\section{REFERENCIAS BIBLIOGRÁFICAS}

ALESINA, A; PEROTTI, R. (1995). "Fiscal expansions and adjustments in OECD countries". Economic policy, vol. 10, n² 21, pp. 205-248.

ÁLVAREZ, S; PRIETO, J.; ROMERO, D. (2003). "Principales rasgos de la evolución del gasto público en España en el periodo 1975-2003". En Álvarez, S. y Salinas, J.(coords.): El gasto público en la democracia. Estudios en el XXV aniversario de la Constitución Española de, 1978, p. 47-76.

ANDRÉS, J.; DE LA FUENTE, A.; DOMÉNECH, R. (2016). Notas para una política fiscal en la salida de la crisis. FEDEA, 2016.

ARELLANO, M.; BENTOLILA, S. (2009). La burbuja inmobiliaria: causas y responsables. La Crisis de la Economía Española: Lecciones y Propuestas. FEDEA.

BAJO-RUBIO, O., DÍAZ-ROLDÁN, C., \& ESTEVE, V. (2006). Is the budget deficit sustainable when fiscal policy is non-linear? The case of Spain. Journal of Macroeconomics, 28(3), 596-608.

BAJO-RUBIO, O., DÍAZ-ROLDÁN, C., \& ESTEVE, V. (2004). Searching for threshold effects in the evolution of budget deficits: An application to the Spanish case. Economics Letters, 82(2), 239-243.

BARRO, R.; GORDON, D. (1981). "A positive theory of monetary policy in a natural-rate model". NBER Working Paper No. 807.

CONDE-RUIZ, J.; MARÍN, C. (2013). "La crisis fiscal en España". Anuario internacional CIDOB, p. 223-230.

DE COS, P. (2010). "El papel de la política fiscal en la crisis económica". Presupuesto y Gasto Público, vol. 59, pp. 39-54.

DE GRAUWE, P. (2014). Economics of monetary union. Oxford: Oxford University Press (10 ed.).

DE MOLINA, J. (2014). "La acción del BCE y la economía española en los quince primeros años del euro". Boletín Económico, [Boletín, 02/2014], pp. 43-56.

DOMÉNECH, R.; GÓMEZ, V. (2005). "Ciclo económico y desempleo estructural en la economía española”. Investigaciones económicas, vol. 29, nº 2, pp. 259-288.

ESPUELAS, S. (2013). "La evolución del gasto social público en España, 18502005". Estudios de Historia Económica, vol. 63, pp. 39-51 y 85-99.

MARTÍNEZ, I.; PALMA, L. (2015). "La transición hacia un modelo de pensiones de capitalización nocional. Evidencia empírica para el caso español (2002-2014)". Anales de Economía Aplicada 2025, $n^{\circ}$ XXIX, pp. 798-814.

MULAS, C.; ONRUBIA, J.; SALINAS, J. (2003). "Política presupuestaria en España (1978-2003)". En Álvarez, S. y Salinas, J.(coords.): El gasto público en la democra- 
cia. Estudios en el XXV aniversario de la Constitución Española de, 1978, pp. 383406.

MULAS-GRANADOS, C.; ONRUBIA, J.; SALINAS-JIMENEZ, J. (2009). "Do Budget Institutions Matter?: Fiscal Consolidation in the New EU Member States". Eastern European Economics, vol. 47, no 1, p. 60-91.

POTERBA, J. M. (1996a). Budget institutions and fiscal policy in the US states. NBER Working Paper No. 5449,

POTERBA, J. M. (1996b). "Do budget rules work?". NBER Working Paper No. 5550.

RUBIO, O. (2007). "El marco de la política fiscal en España: sostenibilidad del déficit público e implicaciones de la UEM". Información Comercial Española, ICE: Revista de economía, n 837, pp. 57-70.

STIGLER, G. J. (1974). "Incentives and Risk Sharing in Sharecropping". Review of Economic Studies, vol. 41(2), pp. 219-256.

STIGLER, G. J. (1975). "Incentives, Risk, and Information: Notes Toward a Theory of Hierarchy". Bell Journal of Economics and Management Science, vol. 6(2), pp. 552579.

VERGÉS, J. (2013). Las privatizaciones de empresas públicas en España. (publicación on line del propio Joaquim Vergés i Jaime, bajo licencia creative commons).

VLAICU, R.; WHALLEY, A. (2011). "Do housing bubbles generate fiscal bubbles?". Public Choice, vol. 149(1), pp. 89-108. 